\title{
BMJ
}

\section{Effects of B vitamins and omega 3 fatty acids on cardiovascular diseases: a randomised placebo controlled trial}

\author{
Pilar Galan, research director, ${ }^{1}$ Emmanuelle Kesse-Guyot, research fellow, ${ }^{1}$ Sébastien Czernichow, associate \\ professor, ${ }^{1,2}$ Serge Briancon, professor, ${ }^{3}$ Jacques Blacher, professor, ${ }^{1,4}$ Serge Hercberg, professor ${ }^{1,2}$ for the \\ SU.FOL.OM3 Collaborative Group
}

\begin{abstract}
UMR U557 Inserm; U1125 Inra: Cnam; Université Paris 13, CR NH IdF, F-93017 Bobigny, France ${ }^{2}$ Département de Santé publique, Hôpital Avicenne, 93017, F-

Bobigny, France

${ }^{3}$ EA 4003, Ecole de Santé publique, Epidémiologie clinique, Faculté de Médecine, CHU Nancy, France

${ }^{4}$ Université Paris-Descartes, Faculté de Médecine; AP-HP. Hôtel-Dieu, Centre de Diagnostic et Thérapeutique, Paris, France

Correspondence to: P Galan, U557 INSERM/INRA/CNAM/UP13, SMBH,

74, rue Marcel Cachin, 93017

Bobigny, France

p.galan@uren.smbh.univ-paris13. $\mathrm{fr}$
\end{abstract}

Cite this as: BMJ 2010;341:c6273 doi:10.1136/bmj.c6273

\section{ABSTRACT}

Objective To investigate whether dietary

supplementation with B vitamins or omega 3 fatty acids, or both, could prevent major cardiovascular events in patients with a history of ischaemic heart disease or stroke.

Design Double blind, randomised, placebo controlled trial; factorial design.

Setting Recruitment throughout France via a network of 417 cardiologists, neurologists, and other physicians.

Participants 2501 patients with a history of myocardial infarction, unstable angina, or ischaemic stroke. Intervention Daily dietary supplement containing 5-methyltetrahydrofolate $(560 \mu \mathrm{g})$, vitamin B-6 (3 mg), and vitamin B-12 $(20 \mu \mathrm{g})$ or placebo; and containing omega 3 fatty acids ( $600 \mathrm{mg}$ of eicosapentanoic acid and docosahexaenoic acid at a ratio of $2: 1$ ) or placebo. Median duration of supplementation was 4.7 years. Main outcome measures Major cardiovascular events, defined as a composite of non-fatal myocardial infarction, stroke, or death from cardiovascular disease.

Results Allocation to B vitamins lowered plasma homocysteine concentrations by $19 \%$ compared with placebo, but had no significant effects on major vascular events (75 v 82 patients, hazard ratio, 0.90 (95\% confidence interval 0.66 to $1.23, \mathrm{P}=0.50)$ ). Allocation to omega 3 fatty acids increased plasma concentrations of omega 3 fatty acids by $37 \%$ compared with placebo, but also had no significant effect on major vascular events ( 81 $v 76$ patients, hazard ratio 1.08 ( 0.79 to $1.47, \mathrm{P}=0.64)$ ). Conclusion This study does not support the routine use of dietary supplements containing B vitamins or omega 3 fatty acids for prevention of cardiovascular disease in people with a history of ischaemic heart disease or ischaemic stroke, at least when supplementation is introduced after the acute phase of the initial event. Trial registration Current Controlled Trials ISRCTN41926726.

\section{INTRODUCTION}

Observational studies have reported inverse associations of cardiovascular disease with dietary intake or plasma concentrations of $\mathrm{B}$ vitamins (folate and vitamin B-6) and omega 3 polyunsaturated fatty acids. ${ }^{1-6}$ Moderately elevated concentrations of plasma total homocysteine have been associated with higher risks of coronary heart disease and stroke, ${ }^{7-12}$ and dietary supplementation with folic acid and vitamin B-12 typically lowers plasma total homocysteine concentration by about $25-30 \%,{ }^{13}$ raising the prospect that dietary supplementation with these $\mathrm{B}$ vitamins might reduce the risk of coronary heart disease and stroke. ${ }^{14}$

Several large scale trials have examined the effects of supplementation with B vitamins on cardiovascular disease, but none has reported any significant effects on risk of cardiovascular disease. ${ }^{15-23}$ Possible reasons for the failure of these trials to show any significant effects on vascular disease include lack of statistical power to detect treatment effects (owing to an insufficient number of participants or duration of treatment), attenuation of the effects of B vitamins by mandatory folic acid fortification or by widespread use of supplements containing folic acid among trial participants, or that homocysteine is not causally related to vascular disease.

Observational studies have also reported inverse associations of cardiovascular disease with dietary intake or plasma concentrations of omega 3 fatty acids (mainly eicosapentanoic acid and docosahexaenoic acid), suggesting that supplementation with omega 3 fatty acids might exert protective effects on cardiovascular disease. ${ }^{24-28}$ These fatty acids have been shown to have beneficial effects on several cardiovascular risk factors-including blood pressure, plasma triglyceride concentration, and markers of thrombosis and inflammation - and may also have antiarrhythmic effects. ${ }^{24-29}$ Although some trials involving patients with a history of cardiovascular diseases or with high levels of cardiovascular risk factors have reported positive effects of omega 3 fatty acids on cardiovascular events, ${ }^{3031}$ other trials have reported no effects on arrhythmia or mortality. ${ }^{2932-34}$

The aims of the Supplémentation en Folates et Omega-3 (SU.FOL.OM3) trial were to investigate 
whether dietary supplementation with homocysteine lowering B vitamins or omega 3 fatty acids, or both, could prevent major cardiovascular events in patients with a history of ischaemic heart disease or stroke.

\section{METHODS}

Study design

The SU.FOL.OM3 trial was a multicentre, double blind, randomised trial with a placebo controlled factorial design that evaluated the separate and combined effects of daily dietary supplementation with B vitamins and omega 3 fatty acids for the prevention of cardiovascular disease. Using a $2 \times 2$ factorial design, we examined the effects of a daily dietary supplement containing 5-methyltetrahydrofolate $(560 \mu \mathrm{g})$, vitamin B-6 $(3 \mathrm{mg})$ and B-12 (20 $\mu \mathrm{g})$ versus placebo, and a supplement containing omega 3 polyunsaturated fatty acids $(600 \mathrm{mg}$ of eicosapentanoic acid and docosahexaenoic acid at a ratio of $2: 1)$ versus placebo. The supplements were provided without charge by Merck Eprova AG (5-methyltetrahydrofolate), Roche Laboratory (vitamins B-6 and B-12), and Pierre Fabre (omega 3 fatty acids). The gelatin capsules were manufactured by Catalent Pharma Solutions (Beinheim, France). The study protocol was approved by the Consultation Committee for the Protection of Participants in Biomedical Research of the Paris-Cochin Hospital and by the French National Information and Citizen Freedom Committee. All participants provided written informed consent.

\section{Study population and design}

Participants with a history of cardiovascular disease were recruited via a network of 417 cardiologists, neurologists, and other physicians in 257 centres throughout France. Men and women aged $45-80$ years who had had an acute coronary or cerebral ischaemic event within the 12 months before randomisation were eligible to participate.

A coronary event was defined as either myocardial infarction or acute coronary syndrome. Myocardial infarction (ICD-10 (international classification of diseases, 10th revision) codes I21.0-I21.9) was defined on the basis of two or more of the criteria-typical chest pain, electrocardiographic changes consistent with myocardial infarction, and cardiac enzyme increase. Acute coronary syndrome without myocardial infarction (ICD-10 codes I20.0-I20.1) was initially defined by the presence of three criteria-typical chest pain, electrocardiographic changes consistent with coronary artery disease without myocardial infarction, and evidence of coronary artery disease (myocardial infarction, angina with angiographic evidence of stenosis $>50 \%$ in one or more coronary arteries, or angina pectoris corroborated by coronary angiography or exercise testing, or coronary angioplasty or coronary artery bypass graft procedure). In 2003 the inclusion criteria were amended to include suspected acute coronary syndrome without characteristic electrocardiographic evidence of myocardial infarction provided there was angiographic evidence of coronary artery disease.

An acute cerebral ischaemic event was defined as an ischaemic cerebrovascular accident based on clinical criteria confirmed by computed tomography or magnetic resonance imaging and a Rankin score $\leq 3$ at inclusion (ICD-10 codes I63.0-I63.9). Individuals with transient ischaemic attacks were not eligible for inclusion.

\section{Exclusion criteria}

Exclusion criteria included age ( $<45$ years or $>80$ years), ill defined diagnosis of cardiovascular disease, inability or unwillingness to comply with study treatment, and disease or treatment that might interfere with metabolism of homocysteine or omega 3 fatty acids, in particular methotrexate for treating cancer or rheumatoid arthritis and chronic renal failure (plasma creatinine concentration $>200 \mu \mathrm{mol} / \mathrm{l}$ or creatinine clearance $<40 \mathrm{ml} / \mathrm{min}$ ).

\section{Randomisation and blinding}

Included participants were randomly assigned to receive $\mathrm{B}$ vitamins alone, omega 3 fatty acids alone, both active treatments, or placebo for both treatments. Study treatment was given as two capsules to be taken once daily. Randomisation was performed by means of a computerised block sequence stratified by three age groups (44-54, 55-64, and 65-80 years), sex, prior disease at enrolment (myocardial infarction, acute coronary syndrome, or ischaemic stroke) and recruitment centre. Permuted block randomisation (with block size randomly selected as 8) was used. Patients, clinicians, trial coordinators, and outcome investigators were blinded to treatment allocation. The allocation of participants was programmed by the statistical coordinating centre. Once participants were randomised, the coordinating centre sent them sufficient treatment capsules for one year (and repeated yearly) in an appropriately labelled package.

\section{Assessment}

Every six months after enrolment, we mailed questionnaires to all the participants, asking about any serious disease outcomes, treatment compliance, presence of cardiovascular risk factors, and adverse effects. A nonmandatory visit was scheduled annually in one of the 257 centres, and participants who were unable or unwilling to attend and who did not return the questionnaire were interviewed by telephone by study physicians. The general practitioners, cardiolologists, or neurologists treating the participants were asked to report any relevant information on health events that might have occurred every six months. Once a possible event was suspected, we sought all relevant medical records, including results of diagnostic tests and procedures, from the treating physician or general practitioner or directly from the participant.

Compliance with treatment was self reported in the biannual questionnaires (or by telephone interview). 


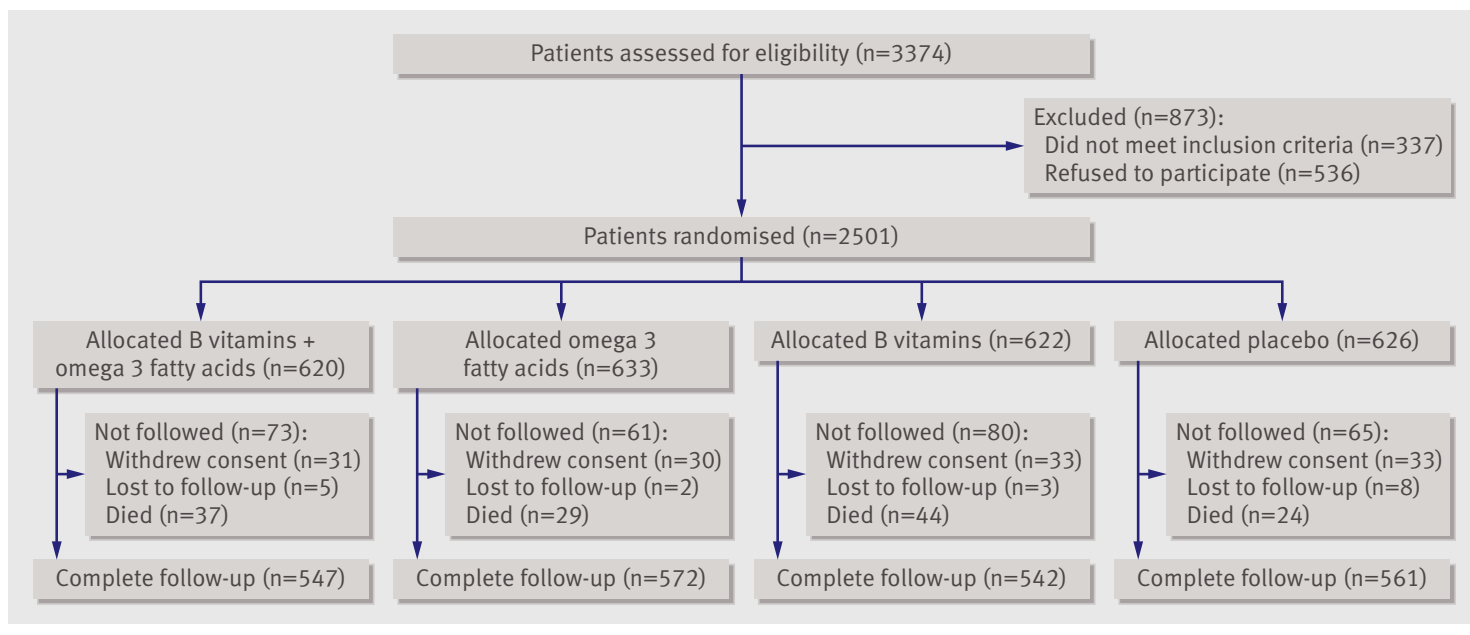

Fig 1 | Flow chart of study participants.

Compliance was defined as taking at least $80 \%$ of the allocated treatment. Blood samples were obtained from all participants at baseline, and from a sample of participants attending their health centre visit at 12 months $(n=2147)$ and at the end of the trial $(n=1160)$ for assessment of plasma concentrations of total homocysteine and pyridoxal phosphate and serum concentrations of folate and vitamin B-12. Fatty acid composition of plasma lipids was also determined by gas chromatography in a random sample $(\mathrm{n}=682)$ at baseline and at 12 months. In addition, all participants had plasma concentrations of cholesterol (total, low density lipoprotein, and high density lipoprotein) and triglycerides and fasting blood glucose concentrations measured at enrolment. Participants were censored on the date of their first major event, death, or, for those without an event, at the end of follow-up on 1 July 2009.

\section{End points}

The primary end point was the first major cardiovascular event-non-fatal myocardial infarction, ischaemic stroke, or death from cardiovascular disease (including fatal myocardial infarction, stroke, sudden death (within one hour of onset of acute symptoms in the absence of violence or accident), aortic dissection, cardiac failure, or other fatal event defined by the medical committee as having a cardiovascular cause). Secondary end points included acute coronary syndrome without myocardial infarction, resuscitation from sudden death, coronary artery bypass surgery, coronary angioplasty, cardiac failure, ventricular arrhythmia, supraventricular arrhythmia, cardiac surgery of any kind, transient ischaemic attack, deep vein thrombosis, pulmonary embolism, carotid surgery or carotid artery angioplasty, peripheral arterial surgery or angioplasty, any vascular procedure, and death from all causes. All events were adjudicated by two independent committees of cardiologists or neurologists who were blinded to treatment allocation. In addition, incident cases of cancer were also recorded, and all cases were confirmed by pathology reports.

\section{Statistical analysis}

The sample size was calculated for the estimated event rate of 0.087 in the placebo group, based on the event rates observed in previous trials in similar populations and in epidemiological studies. ${ }^{35-37}$ No interaction between $\mathrm{B}$ vitamins and omega 3 fatty acids was anticipated. The planned enrolment of 2500 participants with an average follow-up of five years was expected to have more than $90 \%$ power to detect a $10 \%$ reduction in the relative risk of major vascular events associated with B vitamins or omega 3 fatty acids and a 19\% reduction for the combination of omega 3 fatty acids and $\mathrm{B}$ vitamins, given a two sided $\alpha$ value of $0.05 .^{35}$

For analysis of the primary outcome, participants contributed to person time up to the date of diagnosis, date of last completed questionnaire, date of death, or 1 July 2009, whichever occurred first. For analysis of the secondary outcomes, participants who experienced events other than those included in the primary end point were censored at the date of diagnosis. For analyses of revascularisation and other cardiovascular events, participants were counted only if they had not already experienced a primary outcome.

All analyses were conducted according to the principle of intention to treat. The main comparisons were the effects of $B$ vitamins versus placebo and omega 3 fatty acids versus placebo, but the $2 \times 2$ factorial design also allowed comparison between the combined supplementation group with the placebo group. We estimated the hazard ratios and 95\% confidence intervals using Cox proportional hazards models after adjustment for age and sex. We used Kaplan-Meier survival analysis to compare the cumulative incidence of the primary end point by treatment allocation. Assumptions of proportionality were verified graphically.

All the analyses were performed with SAS software (version 8.2). This study is registered with Current Controlled Trials (No ISRCTN41926726). 
Table 1|Baseline characteristics of 2501 trial participants by allocation to dietary supplementation with B vitamins, omega 3 fatty acids, or both. Values are median (interquartile range) except when specified otherwise

\begin{tabular}{|c|c|c|c|c|}
\hline & $\begin{array}{l}\text { B vitamins + omega } 3 \\
\text { fatty acids }(n=620)\end{array}$ & $\begin{array}{l}\text { Omega } 3 \text { fatty acids } \\
\qquad(n=633)\end{array}$ & $\begin{array}{l}\text { B vitamins } \\
(n=622)\end{array}$ & $\begin{array}{l}\text { Placebo } \\
(n=626)\end{array}$ \\
\hline Age (years) & $60.5(53.9-68.9)$ & $60.41(5.7-68.7)$ & $60.7(54.7-68.3)$ & $60.9(54.5-68.1)$ \\
\hline No (\%) of men & $493(79.5)$ & $501(79.2)$ & $497(79.9)$ & $496(79.2)$ \\
\hline \multicolumn{5}{|l|}{ No (\%) with inclusion criteria: } \\
\hline Myocardial infarction & $280(45.2)$ & $300(47.4)$ & $288(46.3)$ & $282(45.0)$ \\
\hline Unstable angina & $176(28.4)$ & $185(29.2)$ & $168(27.0)$ & $184(29.4)$ \\
\hline Stroke & $164(26.4)$ & $148(23.4)$ & $166(26.7)$ & $160(25.6)$ \\
\hline $\begin{array}{l}\text { No }(\%) \text { reaching elementary school level } \\
\text { of education* }\end{array}$ & $375(62.1)$ & $364(59.0)$ & $370(60.8)$ & $376(61.1)$ \\
\hline \multicolumn{5}{|l|}{ No (\%) smoking: } \\
\hline Current smokers & $69(11.4)$ & $70(11.3)$ & $67(10.9)$ & $63(10.1)$ \\
\hline Former smokers & $374(61.5)$ & $368(59.2)$ & $378(61.4)$ & 397 (63.9) \\
\hline Non-smokers & $165(27.1)$ & $183(29.5)$ & $171(27.7)$ & $161(26.0)$ \\
\hline \multicolumn{5}{|l|}{ Blood pressure $(\mathrm{mm} \mathrm{Hg})$ : } \\
\hline Systolic & $130.0(118.0-147.0)$ & $130.5(118.5-149.0)$ & $131.0(117.5-146.5)$ & $132.0(118.5-144.0)$ \\
\hline Diastolic & $82.0(75.0-91.0)$ & $83.0(75.0-91.5)$ & $82.5(74.0-91.5)$ & $81.5(74.5-89.0)$ \\
\hline Body mass index $\left(\mathrm{kg} / \mathrm{m}^{2}\right)$ & $27.1(24.7-29.8)$ & $27.1(25.1-29.7)$ & $27.3(25.0-29.75)$ & $27.2(24.0-29.7)$ \\
\hline Waist:hip ratio & $0.95(0.91-0.99)$ & $0.96(0.91-1.00)$ & $0.96(0.91-0.99)$ & $0.96(0.91-1.00)$ \\
\hline \multicolumn{5}{|l|}{ No (\%) using medication: } \\
\hline$\beta$ blockers & $409(66.0)$ & $431(68,1)$ & $422(67.9)$ & $428(68.4)$ \\
\hline Calcium and channel blockers & $86(13.9)$ & $103(16.3)$ & $79(12.7)$ & $86(13.7)$ \\
\hline Lipid lowering agents & $531(85.7)$ & $544(85.9)$ & $518(83.3)$ & $544(86.9)$ \\
\hline Aspirin or antiplatelet agents & 569 (91.8) & $595(94.0)$ & 584 (93.9) & 588 (93.9) \\
\hline ACE inhibitors & $340(54.8)$ & $331(52.3)$ & $328(52.7)$ & $342(54.6)$ \\
\hline Angiotensin II receptor blockers & $61(9.8)$ & $44(7.0)$ & $64(10.3)$ & $70(11.2)$ \\
\hline \multicolumn{5}{|l|}{ Plasma concentrations (mmol/l): } \\
\hline Total cholesterol & $4.5(3.9-5.3)$ & $4.5(3.9-5.4)$ & $4.6(3.9-5.3)$ & $4.5(3.9-5.1)$ \\
\hline HDL cholesterol & $1.2(1.0-1.4)$ & $1.2(1.0-1.3)$ & $1.2(1.0-1.4)$ & $1.1(1.0-1.3)$ \\
\hline LDL cholesterol & $2.7(2.2-3.3)$ & $2.7(2.2-3.3)$ & $2.7(2.2-3.3)$ & $2.6(2.2-3.2)$ \\
\hline Fasting glucose & $5.4(5.1-6.1)$ & $5.4(5.0-5.9)$ & $5.4(5.1-5.9)$ & $5.4(5.0-5.9)$ \\
\hline Triglycerides & $1.2(0.9-1.6)$ & $1.2(0.9-1.6))$ & $1.3(0.9-1.7))$ & $1.1(0.9-1.7))$ \\
\hline Biochemical characteristics $†$ & $(n=611)$ & $(n=622)$ & $(n=612)$ & $(n=616)$ \\
\hline Serum folate $(\mathrm{ng} / \mathrm{ml})$ & $6.7(5.2-8.7)$ & $6.6(5.1-8.6)$ & $6.7(5.2-8.5)$ & $7.0(5.3-9.0)$ \\
\hline Plasma vitamin B-6 (nmol/l) & $37.2(28.0-50.6)$ & $38.7(27.8-53.8)$ & $38.0(29.1-52.7)$ & $37.7(28.5-53.5)$ \\
\hline Serum vitamin B-12 (pg/ml) & $361(291-455)$ & $365(290-468)$ & $359(298-455)$ & $376(306-474)$ \\
\hline Plasma total homocysteine $(\mu \mathrm{mol} / \mathrm{l})$ & $12.9(10.7-16.0)$ & $12.9(10.9-15.8)$ & $13.0(11.2-16.0)$ & $12.6(10.4-15.5)$ \\
\hline Creatinine $(\mu \mathrm{mol} / \mathrm{l})$ & $78.0(70.0-87.0)$ & $77.0(68.0-88.0)$ & $78.0(70.0-88.0)$ & $78.0(69.0-88.0)$ \\
\hline
\end{tabular}

\section{RESULTS}

\section{Characteristics of the participants}

Between 1 February 2003 and 1 June 2007, 2501 participants (1987 men and 514 women) were recruited. Overall, the mean (SD) age of participants was 60.9 (8.8) years for men and $63.2(9.7)$ years for women. Of the 2501 participants, $1150(46 \%)$ had had a prior myocardial infarction, $713(28 \%)$ an acute coronary syndrome without myocardial infarction, and 638 $(26 \%)$ an ischaemic stroke. The median time between the acute event and randomisation in the trial was 101 days. Participants were randomly assigned to one of four treatments: B vitamins ( $\mathrm{n}=622)$, omega 3 fatty acids $(\mathrm{n}=633), \mathrm{B}$ vitamins and omega 3 fatty acids $(\mathrm{n}=$ $620)$, or double placebo $(\mathrm{n}=626)$ (fig 1). The four groups were well balanced with respect to the baseline characteristics, risk factors, and medication use (table 1). The median follow-up time was 4.7 years (mean 4.2 (SD 1.0) years) with a total of 10656 person years. All participants completed their scheduled treatment by 1 July 2009 .

\section{Compliance and side effects}

The overall response rate for return of completed questionnaires was $99 \%, 96 \%, 94 \%$, and $95 \%$ at 6,12 , and 24 months and at the end of the trial, respectively. About $86 \%$ of those who returned a questionnaire reported that they were compliant with the study treatment (defined as taking at least $80 \%$ of the allocated treatment), and compliance was similar in all four 
Table 2 | Participants' concentrations of biochemical markers at baseline, at one year, and at the end of treatment by allocation to dietary supplementation with B vitamins, omega 3 fatty acids, or both. Values are medians (interquartile ranges)

\begin{tabular}{|c|c|c|c|c|}
\hline & $\begin{array}{l}\text { B vitamins } \\
+ \text { omega } 3 \\
\text { fatty acids }\end{array}$ & $\begin{array}{l}\text { Omega } 3 \\
\text { fatty acids }\end{array}$ & B vitamins & Placebo \\
\hline \multicolumn{5}{|l|}{$\begin{array}{l}\text { Plasma total homocysteine } \\
(\mu \mathrm{mol} / \mathrm{l}) \text { : }\end{array}$} \\
\hline Baseline* & $12.9(10.7-16.0)$ & $12.9(10.9-15.8)$ & $13.0(11.2-16.0)$ & $12.6(10.4-15.5)$ \\
\hline 1 yeart & $9.8(8.2-11.5)$ & $12.3(10.3-15.1)$ & $9.7(8.1-11.8)$ & $12.1(9.7-14.8)$ \\
\hline End of supplementation $\ddagger$ & $11.9(10.3-14.0)$ & $14.2(12.0-17.6)$ & $11.4(9.9-14.4)$ & $14.5(12.4-18.3)$ \\
\hline \multicolumn{5}{|l|}{ Serum folate $(\mathrm{ng} / \mathrm{ml})$ : } \\
\hline Baseline* & $6.7(5.2-8.7)$ & $6.6(5.1-8.6)$ & $6.7(5.2-8.5)$ & $7.0(5.3-9.0)$ \\
\hline 1 yeart & $16.9(12.2-21.9)$ & $6.8(5.3-8.7)$ & $16.5(12.0-21.9)$ & $6.7(5.2-8.4)$ \\
\hline End of supplementation $\ddagger$ & $16.1(12.3-1.5)$ & $6.4(4.9-8.4)$ & $15.4(11.4-19.4)$ & $6.5(5.2-8.1)$ \\
\hline \multicolumn{5}{|l|}{ Plasma vitamin B-6 (nmol/l): } \\
\hline Baseline* & $37.2(28.0-50.6)$ & $38.7(27.8-53.8)$ & $38.0(29.1-52.7)$ & $37.7(28.5-53.5)$ \\
\hline 1 yeart & $81.1(57.4-106.2)$ & $39.4(28.9-53.8)$ & $69.4(50.5-92.1)$ & $37.3(28.2-53.2)$ \\
\hline End of supplementation $\ddagger$ & $87.3(58.0-121.3)$ & $38.2(28.2-52.5)$ & $76.3(49.7-102.4)$ & $36.9(27.6-50.9)$ \\
\hline \multicolumn{5}{|l|}{ Serum vitamin B-12 $(\mathrm{pg} / \mathrm{ml})$ : } \\
\hline Baseline* & $361(291-455)$ & $365(290-468)$ & $359(298-455)$ & $376(306-474)$ \\
\hline 1 yeart & $506(405-646)$ & 381 (296-488) & $491(390-639)$ & $378(303-481)$ \\
\hline End of supplementation $\ddagger$ & $504(397-620)$ & $367(286-468)$ & $497(390-615)$ & $370(312-469)$ \\
\hline \multicolumn{5}{|c|}{ Fatty acid composition of plasma lipids (\% of total)§ } \\
\hline \multicolumn{5}{|l|}{ Eicosapentanoic acid: } \\
\hline Baseline & $1.15(0.80-1.69)$ & $1.14(0.83-1.71)$ & $1.12(0.75-1.68)$ & $1.26(0.84-1.81)$ \\
\hline 1 year & $2.08(1.65-2.76)$ & $2.15(1.77-2.75)$ & $1.16(0.78-1.68)$ & $1.20(0.88-1.66)$ \\
\hline \multicolumn{5}{|l|}{ Docosahexaenoic acid: } \\
\hline Baseline & $2.53(2.05-3.28)$ & $2.55(2.04-3.23)$ & $2.53(2.00-3.23)$ & $2.70(2.15-3.36)$ \\
\hline 1 year & $3.07(2.70-3.74)$ & $3.12(2.70-3.76)$ & $2.55(1.96-3.23)$ & $2.77(2.06-3.29)$ \\
\hline \multicolumn{5}{|l|}{$\begin{array}{l}\text { Eicosapentanoic }+ \\
\text { docosahexaenoic acids: }\end{array}$} \\
\hline Baseline & $3.68(2.93-4.97)$ & $3.73(2.92-4.91)$ & $3.64(2.86-4.78)$ & $4.04(2.99-5.08)$ \\
\hline 1 year & $5.13(4.42-6.38)$ & $5.34(4.53-6.52)$ & $3.66(2.85-4.99)$ & $3.92(2.99-4.81)$ \\
\hline \multicolumn{5}{|c|}{$\begin{array}{l}{ }^{*} n=2461 \text { (respectively } 611,622,612 \text {, and } 616 \text { for the four groups). } \\
t n=2147 \text { (respectively } 531,544,534 \text {, and } 538 \text { for the four groups). } \\
\ddagger n=1160 \text { (respectively } 282,292,294 \text {, and } 292 \text { for the four groups). } \\
\S n=682 \text { (respectively } 163,173,177 \text {, and } 169 \text { for the four groups). }\end{array}$} \\
\hline
\end{tabular}

groups $(87 \%, 86 \%, 86 \%$, and $86 \%)$. Side effects (chiefly gastrointestinal disturbances, nausea, and cutaneous reactions) accounted for $2.1 \%$ of participants stopping treatment $(2.6 \%$ in the group taking omega 3 fatty acids group, $2.0 \%$ in the $\mathrm{B}$ vitamins group, and $1.6 \%$ in the placebo group).

Effect of intervention on B vitamin status and fatty acid profiles

The median (interquartile range) baseline concentrations of serum folate were $6.7(5.2-8.7) \mathrm{ng} / \mathrm{ml}$, vitamin B-12 was $365(296-463) \mathrm{pg} / \mathrm{ml}$, and plasma total homocysteine was $12.8(10.8-15.8) \mu \mathrm{mol} / \mathrm{l}$. Allocation to B vitamins was associated with a $20 \%$ lower $(2.5 \mu \mathrm{mol} / \mathrm{l})$ median plasma total homocysteine concentration at 1 year compared with those allocated placebo, and this difference was $19 \%(2.7 \mu \mathrm{mol} / \mathrm{l})$ at the end of the trial (table 2). Allocation to B vitamins was associated with $146 \%$ increase in serum folate, $35 \%$ increase in serum vitamin B-12, and $116 \%$ increase in plasma vitamin B-6. Allocation to omega 3 fatty acids was associated with a $37 \%$ increase in median plasma concentrations of these fatty acids at one year compared with those allocated to placebo.

Effects of B vitamins on primary and secondary end points Primary end point

During a median of 4.7 years of follow-up, 157 participants $(6.3 \%)$ experienced a major confirmed cardiovascular event, with 20 individuals experiencing more than one cardiovascular event. Allocation to B vitamins was not associated with any significant effect on major vascular events (75 $v 82$ individuals, hazard ratio 0.90 (95\% confidence interval 0.66 to 1.23$)$, $\mathrm{P}=0.50$; fig 2). $\mathrm{B}$ vitamins had no significant effect on the cumulative incidence of the primary end points throughout the scheduled treatment period (fig 3).

\section{Secondary end points}

Among the secondary outcomes, there were 60 cases of non-fatal myocardial infarction, 57 cases of stroke, 117 deaths (40 due to cardiovascular causes), and 436 additional cardiovascular events, including coronary angioplasty $(\mathrm{n}=174)$, coronary artery bypass surgery $(\mathrm{n}=38)$, acute coronary syndrome without myocardial infarction $(n=37)$, supraventricular arrhythmia $(n=33)$, and acute cardiac failure $(\mathrm{n}=31)$.

Allocation to B vitamins had no significant effect on non-fatal myocardial infarction (28 v 32 patients, hazard ratio 0.88 ( 0.53 to 1.46$), \mathrm{P}=0.61$; fig 2$)$, but it was associated with fewer stroke events (21 v 36 patients, hazard ratio 0.57 (0.33 to 0.97$), \mathrm{P}=0.04$ ). There were no significant differences in the rates of all other cardiovascular events, analysed individually or combined. However, supplementation with B vitamins was associated with a non-significantly higher mortality from cardiovascular causes (26 $v 14$ patients, hazard ratio 1.81 (0.95 to 3.47$), \mathrm{P}=0.07$ ) and a significantly higher risk of death from any cause (72 $v 45$ patients, hazard ratio 1.55 (1.07 to 2.25$), \mathrm{P}=0.02)$. Furthermore, allocation to $\mathrm{B}$ vitamins did not have any significant effects on cancer morbidity (92 v 77patients, hazard ratio 1.19 (0.88 to 1.60$), \mathrm{P}=0.27$ ).

Effect of omega 3 fatty acids on primary and secondary end points

Allocation to omega 3 fatty acids was not associated with any significant effect on major vascular events (81 v 76 patients, hazard ratio 1.08 (0.79 to 1.47 ), $\mathrm{P}=0.64$; fig 4 ). Moreover, there were no significant differences in the cumulative incidence of the primary end point between the active and placebo groups at any time during follow-up (fig 3).

In addition, allocation to omega 3 fatty acids had no significant effect on any secondary end points, including other cardiovascular events and mortality from all causes (fig 4 ), nor on cancer morbidity (88v81 patients, hazard ratio 1.10 (0.81 to 1.48$), \mathrm{P}=0.55)$.

\section{DISCUSSION}

In this trial we found no significant effects of daily dietary supplementation with B vitamins or with omega 3 fatty acids on risk of major cardiovascular events in 


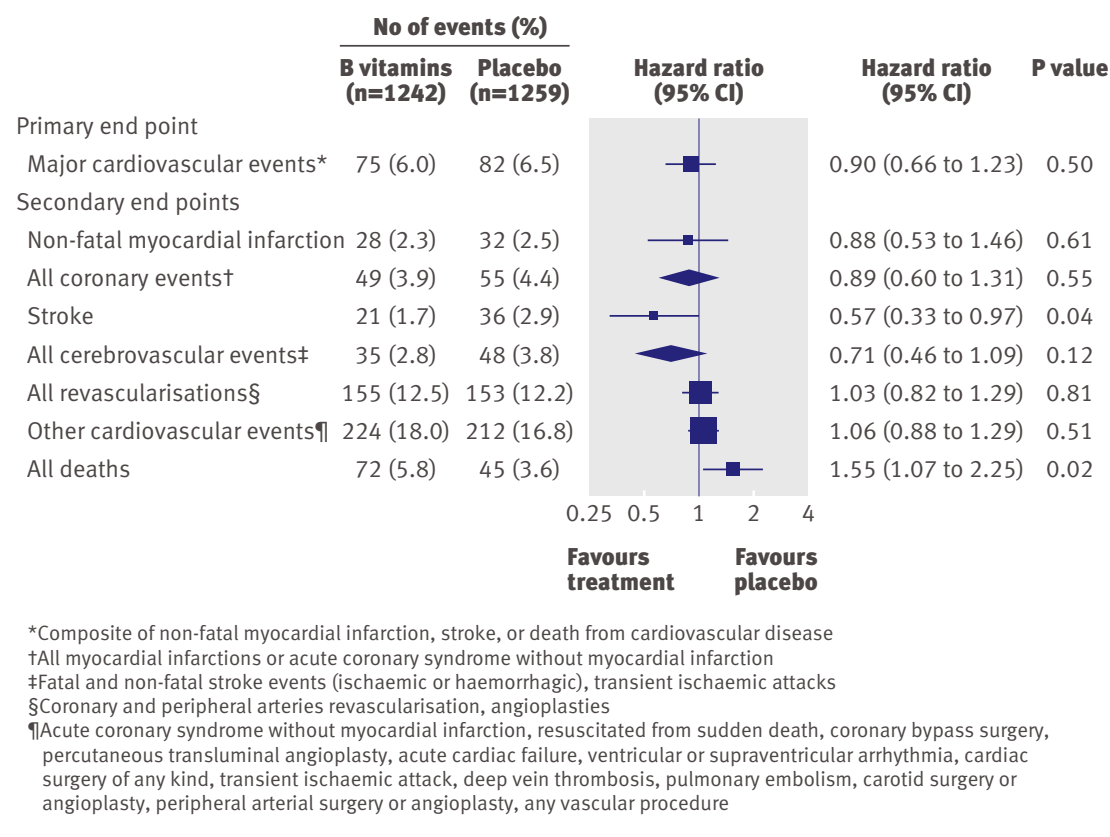

Fig 2 | Effect of dietary supplementation with B vitamins on cardiovascular events and mortality (adjusted for age and sex) formulation of folic acid. Previous trials used higher doses of B vitamins ${ }^{15-23}$ and omega 3 polyunsaturated acids. ${ }^{31} \mathrm{~A}$ meta-analysis of trials that assessed the effects of folic acid on blood homocysteine concentrations showed that daily supplementation with $0.5-5 \mathrm{mg}$ of folic acid reduced homocysteine concentrations by about a quarter, and the addition of vitamin B-12 $(20 \mu \mathrm{g}$ to $1 \mathrm{mg}$ daily) to folic acid reduced blood homocysteine concentration by a further $7 \% .^{38}$

Instead of folic acid, we used 5-methyltetrahydrofolate, which is the predominant form present in circulation and the most abundant natural folate form and is as effective as folic acid in decreasing blood homocysteine concentration and is unlikely to mask vitamin B-12 deficiency. ${ }^{39}$ The dose of omega 3 fatty acids we used corresponded to a diet containing a large amount of fatty fish, which has been associated with a reduced risk of cardiovascular diseases in observational studies. ${ }^{3242627}$

\section{Strengths and limitations of the trial}

Our trial had several important strengths. First, the trial was carried out in France, a country with no mandatory fortification of foods with folic acid or widespread use of folic acid supplements, both of which may have complicated many other trials of B vitamin supplementation for prevention of vascular disease. ${ }^{15-23}$ Second, none of the previous trials assessed the effects of 5methyltetrafolate, which has a closer resemblance to the naturally occurring 5-methyltetrahydrofolic acid and has been shown to be as effective as folic acid but without the potential disadvantage of masking anaemia from vitamin B-12 deficiency. ${ }^{39}$ Other strengths of the study include the high self reported compliance with treatment (corroborated by increased blood concentrations of B vitamins or omega 3 polyunsaturated fatty acids, and lower plasma homocysteine concentrations in the B vitamin supplementation groups after treatment), the small number of participants lost to follow-up, the availability of complete endpoint data; and the adjudication of end points by professionals blinded to treatment allocation.

However, the trial included a relatively modest number of participants and was continued for relatively short duration to provide appropriate statistical power to detect effects on major vascular events. In particular, the observed number of major vascular events was 15\% lower than expected, which adversely affected the statistical power to detect a 10\% difference in major vascular events. Consequently, we cannot exclude the possibility that the duration of supplementation and follow-up and the doses used for B vitamins and omega 3 polyunsaturated fatty acids were insufficient. While the biochemical analysis was carried out in a subsample of the trial population, it is possible that this subset with biochemical measures had better compliance than the rest of the participants, which may have led to overestimation of the differences in plasma homocysteine concentrations achieved in the overall trial population.
Fig 3 | Kaplan-Meier curves for cumulative incidence of first major cardiovascular event (non-fatal myocardial infarction, ischaemic stroke, or death from cardiovascular disease) associated with dietary supplementation with B vitamins (top) or omega 3 fatty acids (bottom) 


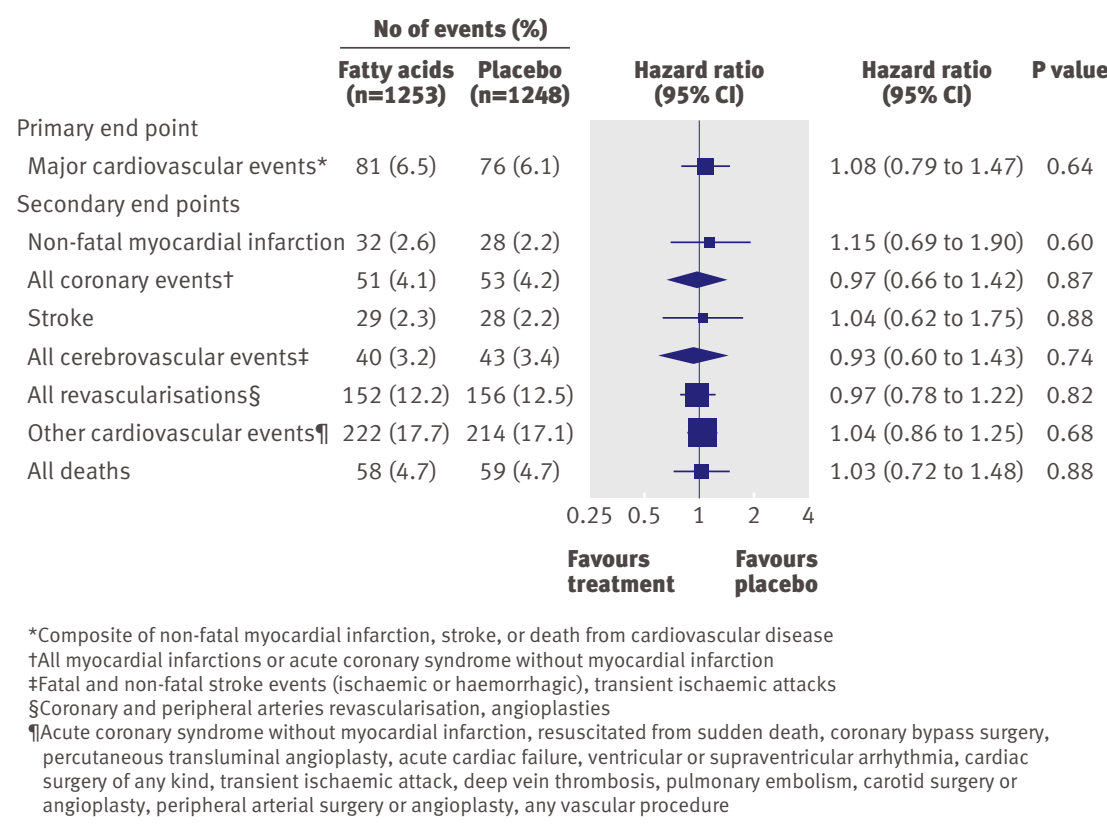

Fig 4 | Effect of dietary supplementation with omega 3 fatty acids on cardiovascular events and mortality (adjusted for age and sex)

\section{Comparisons with other trials}

The absence of any significant effects of B vitamins on major vascular events that we observed is consistent with the results of previous large scale trials of $B$ vitamins in patients with pre-existing vascular disease, ${ }^{15-182223}$ in those at high risk of cardiovascular disease,${ }^{19}$ in patients with end stage renal disease, ${ }^{20}$ or after coronary angiography. ${ }^{21}$ Only the NORVIT trial reported a trend towards an increased rate of primary outcomes among patients receiving $\mathrm{B}$ vitamins. ${ }^{17}$ In addition, two small trials of folic acid and vitamin B- 6 reported a reduction in the rate of restenosis after coronary artery angioplasty but an increase in this rate after coronary stenting. ${ }^{4041}$

In our trial, allocation to B vitamins was associated with a $46 \%$ reduction in the risk of ischaemic stroke among patients assigned to $\mathrm{B}$ vitamins and a trend towards increased cardiovascular mortality, with an unexpected, significant increase in the number of deaths from any cause among patients receiving $B$ vitamins (not specifically linked to cancer). The latter two results must be interpreted with caution, since the number of statistical tests performed on secondary end points was large and the number of events was small, and the confidence intervals around the relative risk estimates are wide.

However, the HOPE-2 trial, of 5522 patients with prior vascular disease treated with $\mathrm{B}$ vitamins for five years, had reported a $24 \%$ reduction in the risk of stroke. ${ }^{18}$ Nevertheless, a reduction in stroke risk was not observed in the Vitamin Intervention for Stroke Prevention (VISP) trial, in which stroke was the primary end point. ${ }^{16}$

In the VISP trial, 3680 patients with non-disabling stroke were randomised to receive high dose vitamins (2.5 mg folic acid, $0.4 \mathrm{mg}$ vitamin B-12, and $25 \mathrm{mg}$ vitamin B-6 daily) or low dose vitamins (20 $\mu \mathrm{g}$ folic acid, $6 \mu \mathrm{g}$ vitamin B-12, and $200 \mu \mathrm{g}$ vitamin B-6 daily), without a placebo group. The trial ended early, and there was no significant effect on the risk of recurrent stroke during the two years of follow-up. It has been suggested that the lack of effect observed in the VISP trial could be explained by the relatively small observed difference in plasma total homocysteine concentrations associated with higher dose vitamins (only 15\%, $13.1 v 11.0 \mu \mathrm{mol} / \mathrm{l}$ ), which was lower than expected, possibly owing to fortification of foods with folic acid. ${ }^{16}$ Furthermore, the study did not include a placebo group, and correction of low levels of serum vitamin B-12 in the low dose group may have attenuated the vitamin effect.

A meta-analysis of eight trials, published in 2007, involving 778 first strokes, showed that folic acid supplementation was associated with an 18\% reduced risk of stroke. ${ }^{42}$

In the stratified analyses, greater beneficial effects were observed in trials with a duration of treatment greater than three years, a decrease in the concentration of plasma total homocysteine of more than $20 \%$, absence of folic acid fortification, and in participants without history of stroke. However, a meta-analysis of eight large homocysteine lowering trials completed before 2009 and involving 37485 participants and 1528 first stroke events reported that lowering homocysteine concentrations had no beneficial effects on first stroke. ${ }^{43}$ The VITATOPS trial, published in 2010, involving 8164 patients with recent stroke or transient ischaemic attack (within the past seven months) treated with B vitamins (2 mg folic acid, $25 \mathrm{mg}$ vitamin $\mathrm{B}-6$, and $0.5 \mathrm{mg}$ vitamin $\mathrm{B}-12$ ) for a median duration of 3.4 years, found no significant reduction in the risk for non-fatal or fatal stroke. ${ }^{23}$

The present trial also showed that omega 3 fatty acids had no significant effects on any of the primary or secondary end points. The results of previous trials of omega 3 fatty acids have been conflicting. In 2004, a meta-analysis involving 36913 participants receiving omega 3 fatty acids in the form of supplement or enriched food for at least six months reported no reduction in total mortality or cardiovascular events. ${ }^{29}$ Subsequently, the effects of omega 3 fatty acids for prevention of cardiovascular disease have been examined in several additional large scale trials.

In the GISSI trial, which included 11324 patients who had had a myocardial infarction within the previous three months, treatment with $1 \mathrm{~g}$ daily of omega 3 fatty acids reduced the risk of death, nonfatal myocardial infarction, and non-fatal stroke by $10 \%$, and the cumulative rate of cardiovascular death, non-fatal myocardial infarction, and non-fatal stroke by $15 \% .{ }^{31}$ Although the trial did not include a placebo group, results provided strong support for an antiarrhythmic effect of the fatty acids.

The JELIS trial of 18645 Japanese participants with elevated serum cholesterol concentrations and receiving statins but without evidence of coronary artery disease reported that supplementation with $1.8 \mathrm{~g}$ daily of 


\section{WHAT IS ALREADY KNOWN ON THIS TOPIC}

Observational studies have reported inverse associations of cardiovascular disease with intake or plasma concentrations of B vitamins (folate and vitamin B-6) and with omega 3 fatty acids

Randomised trials of B vitamins have failed to find any significant effects on vascular disease. Trials of omega 3 fatty acids have produced conflicting results

\section{WHAT THIS STUDY ADDS}

This randomised placebo controlled trial found no significant effects of daily dietary supplementation with B vitamins or with omega 3 fatty acids on risk of major cardiovascular events in patients with established coronary or cerebrovascular disease

The results do not support the routine use of such dietary supplements for prevention of cardiovascular disease in people with a history of ischaemic heart disease or ischaemic stroke, especially when supplementation is introduced after the acute phase of the initial event help of Benoit Gautier for statistical analysis and Gwenael Monot for computer data management.

Contributors: PG, EK-G, SC, and SB had full access to all of the data in the study and take responsibility for the integrity of the data and the accuracy of the analysis. PG, SH, and SB were responsible for the study concept and design. PG, SH, JB, and the SU.FOL.OM3 Study Research Group acquired the data. All the authors participated in analysis and interpretation of the data. PG, SH, and EK-G drafted the manuscript. SC, $J B$, and SB critically revised the manuscript for important intellectual content. EK-G, PG, SH, and SB conducted the statistical analysis. SH and PG obtained funding. PG provided administrative, technical, and material support and supervised the study.

Funding: The SU.FOL.OM3 trial was supported by the French Ministry of Research (R02010JJ), Ministry of Health (DGS), Sodexo, Candia, Unilever Danone, Roche Laboratory, Merck EPROVA GS, and Pierre Fabre Laboratory.

Competing interests: All authors have completed the Unified Competing Interest form at www.icmje.org/coi_disclosure.pdf and declare that they have no relationships with companies that might have an interest in the submitted work in the previous 3 years; they have no other relationships or activities that could appear to have influenced the submitted work. Ethical approval: The study protocol was approved by the Consultation Committee for the Protection of Participants in Biomedical Research of the Paris-Cochin Hospital (CCPPRB No 1933) and the French National Information and Citizen Freedom Committee (CNIL No 901230). Data sharing: No additional data available.

1 Morrison HI, Schaubel D, Desmeules M, Wigle DT. Serum folate and risk of fatal coronary heart disease. JAMA 1996;275:1893-6.

2 Rimm EB, Willett WC, Hu FB, Sampson L, Colditz GA, Manson JE, et al. Folate and vitamin $\mathrm{B} 6$ from diet and supplements in relation to risk of coronary heart disease among women. JAMA 1998;279:359-64.

3 Hu FB, Bronner L, Willett WC, Stampfer MJ, Rexrode KM, Albert CM, et al. Fish and omega-3 fatty acid intake and risk of coronary heart disease in women. JAMA 2002;287:1815-21.

4 Albert CM, Campos H, Stampfer MJ, Ridker PM, Manson JE, Willett WC, et al. Blood levels of long-chain n-3 fatty acids and the risk of sudden death. N Engl J Med 2002;346:1113-8.

5 Erkkilä AT, Lehto S, Pyörälä K, Uusitupa MI. n-3 Fatty acids and 5-y risks of death and cardiovascular disease events in patients with coronary artery disease. Am J Clin Nutr 2003;78:65-71.

6 He K, Merchant A, Rimm EB, Rosner BA, Stampfer MJ, Willett WC, et al. Folate, vitamin B6, and B12 intakes in relation to risk of strok among men. Stroke 2004;35:169-74.

7 Mc Cully KS. Vascular pathology of homocysteinemia: implications for the pathogenesis of arteriosclerosis. Am J Patho 1969;56:111-28.

8 Clarke R, Daly L, Robinson K, Naughten E, Cahalane S, Fowler B, et al. Hyperhomocysteinemia: an independent risk factor for vascular disease. N Engl J Med 1991;324:1149-55.

9 Boushey $\mathrm{Cl}$, Beresford SA, Omenn GS, Motulsky AG. A quantitative assessment of plasma homocysteine as a risk factor for vascular disease. Probable benefits of increasing folic acid intakes. JAMA 1995;274:1049-57.

10 Danesh J, Lewington S. Plasma homocysteine and coronary heart disease. J Cardiovasc Res 1988;5:229-32.

11 Ford ES, Smith SJ, Stroup DF, Steinberg KK, Mueller PW, Thacker SB. Homocyst(e)ine and cardiovascular disease: a systematic review of the evidence with special emphasis on case-control studies and nested case-control studies. Int I Epidemiol 2002;31:59-70.

12 Wald DS, Wald NJ, Morris JK, Law M. Folic acid, homocysteine and cardiovascular disease: judging causality in the face of inconclusive trial evidence. BMJ 2006;333:1114-7.

13 Homocysteine Lowering Trialists' Collaboration. Dose-dependent effects of folic acid on blood concentrations of homocysteine: a meta-analysis of the randomized trials. Am / Clin Nutr 2005;82:806-12.

14 B-Vitamin Treatment Trialists' Collaboration. Homocysteine-lowering trials for prevention of cardiovascular events: a review of the design and power of the large randomized trials. Am Heart 2006;151:282-7.

15 Baker F, Picton D, Blackwood S, Hunt J, Erskine M. Blinded comparison of folic acid and placebo in patients with ischemic hear disease: an outcome trial. Circulation 2002;106 (suppl II):S741.

16 Toole JF, Malinow MR, Chambless LE, Spence JD, Pettigrew LC, Howard VJ, et al. Lowering homocysteine in patients with ischemic stroke to prevent recurrent stroke, myocardial infarction, and death: the Vitamin Intervention for Stroke Prevention (VISP) randomized controlled trial. JAMA 2004;291:565-75. event. 
17 Bonaa KH, Njolstad I, Ueland PM, Schirmer H, Tverdal A, Steigen T, et al. Homocysteine lowering and cardiovascular events after acute myocardial infarction. N Engl J Med 2006;354:1578-88.

18 The Heart Outcomes Prevention Evaluation (HOPE) 2 Investigators Homocysteine lowering with folic acid and B vitamins in vascular disease. N Engl/ Med 2006;354:1567-77.

19 Albert CM, Cook NR, Gaziano JM, Zaharris E, MacFadyen J, Danielson $E$, et al. Effect of folic acid and $B$ vitamins on risk of cardiovascular events and total mortality among women at high risk for cardiovascular disease. JAMA 2008;299:2027-36.

20 Jamison RL, Hartigan P, Kaufman JS, Goldfarb DS, Warren SR, Guarino PD, et al. Effect of homocysteine lowering on mortality and vascular disease in advanced chronic kidney disease and end-stage renal disease: a randomized controlled trial. JAMA 2007;298:1163-70.

21 Ebbing M, Bleie $\varnothing$, Ueland PM, Nordrehaug JE, Nilsen DW, Vollset SE, et al. Mortality and cardiovascular events in patients treated with homocysteine-lowering $B$ vitamins after coronary angiography. $A$ randomized controlled trial. JAMA 2008;300:795-804.

22 Study of the Effectiveness of Additional Reductions in Cholesterol and Homocysteine (SEARCH) Collaborative Group. Effects of homocysteine-lowering with folic acid plus vitamin B12 vs placebo on mortality and major morbidity in myocardial infarction survivors. JAMA 2010;24:2485-94.

23 The VITATOPS Trial Study Group. B-vitamins in patients with recent transient ischaemic attack or stroke in the VITAmins TO Prevent Stroke (VITATOPS) trial: a randomised, double-blind, parallel, placebo-controlled trial. Lancet Neurology 2010;9:855-65.

24 Kris-Etherton PM, Harris WS, Appel LJ. Fish consumption, fish oil, omega- 3 fatty acids, and cardiovascular disease. Circulation 2002;106:2747-57.

25 Bucher HC, Hengstler P, Schindler C, Meier G. N-3 polyunsaturated fatty acids in coronary heart disease: a meta-analysis of randomized controlled trials. Am J Med 2002;112:298-304.

26 Kromhout $\mathrm{D}$. The inverse relation between fish consumption and 20 years mortality from coronary disease. $N$ Engl J Med 1985;312:1205-9.

27 He K, Song Y, Daviglus ML, Liu K, Van Horn L, Dyer AR, et al. Accumulated evidence on fish consumption and coronary heart disease mortality: a meta-analysis of cohort studies. Circulation 2004;109:2705-11.

28 Wang C, Harris WS, Chung M, Lichtenstein AH, Balk EM, Kupelnick B, et al. N-3 fatty acids from fish or fish-oil supplements, but not alphalinoleic acid, benefit cardiovascular disease outcomes in primaryand secondary-prevention studies: a systematic review. Am J Clin Nutr 2006;84:5-17.

29 Hooper L, Thompson RL, Harrison RA, Summerbell CD, Moore H, Worthington HV, et al. Omega 3 fatty acids for prevention and treatment of cardiovascular disease. Cochrane Database Syst Rev 2004;18:CD003177.

30 Burr ML, Fehily AM, Gilbert JF, Rogers S, Holliday RM, Sweetnam PM et al. Effects of changes in fat, fish, and fibre intakes on death and myocardial reinfarction: diet and reinfarction trial (DART). Lancet 1989;2:757-61.

31 Gissi-Prevenzione Investigators. Dietary supplementation with n-3 polyunsaturated fatty acids and vitamin $\mathrm{E}$ after myocardial infarction: results of the GISSI-Prevenzione Trial. Lancet 1999;354:447-55.

32 Raitt MH, Connor WE, Morris C, Kron J, Halperin B, Chugh SS, et al. Fish oil supplementation and risk of ventricular tachycardia and ventricular fibrillation in patients with implantable defibrillators: a randomized controlled trial. JAMA 2005;293:2884-91.

33 Brouwer IA, Raitt MH, Dullemeijer C, Kraemer DF, Zock PL, Morris C, et al. Effect of fish oil on ventricular tachyarrhythmia in three studies in patients with implantable cardioverter defibrillators. Eur Heart J 2009;30:820-6.

34 Burr ML, Ashfield-Watt PA, Dunstan FD, Fehily AM, Breay P, Ashton T, et al. Lack of benefit of dietary advice to men with angina: results of a controlled trial. Eur J Clin Nutr 2003;57:193-200.

35 Galan P, Briancon S, Blacher J, Czernichow S, Hercberg S. The SU. FOL.OM3 Study: a secondary prevention trial testing the impact of supplementation with folate and B-vitamins and/or omega-3 PUFA on fatal and non fatal cardiovascular events, design, methods and participants characteristics. Trials 2008;9:1-9.

36 Yusuf S, Sleight P, Pogue J, Bosch J, Davies R, Dagenais G. Effects of an angiotensin-converting-enzyme inhibitor, ramipril, on cardiovascular events in high-risk patients. The Heart Outcomes Prevention Evaluation Study Investigators. N Engl J Med 2000;342:145-53.

37 Homocysteine Studies Collaboration. Homocysteine and risk of ischemic heart disease and stroke: a meta-analysis. JAMA 2002;288:2015-22

38 Homocysteine Lowering Trialists' Collaboration. Lowering blood homocysteine with folic acid based supplement: meta-analysis of randomised trials. BMJ 1998;316:894-8.

39 Pentieva K, McNulty H, Reichert R, Ward M, Strain J, McKillop D, et al. The short term bioavailabilities of [6S]-5-methyltetrahydrofolate and folic acid are equivalent in men. J Nutr 2004;134:580-5.

40 Schnyder G, Roffi M, Pin R, Roffi M, Flammer Y, Hess OM. Decreased rate of coronary restenosis after lowering of plasma homocysteine levels. N Engl J Med 2001;345:1593-600.

41 Lange H, Suryapranata H, De Luca G, Börner C, Dille J, Kallmayer K, et al. Folate therapy and in-stent restenosis after coronary stenting. $N$ Engl J Med 2004;350:2673-81.

42 Wang X, Qin X, Demirtas H, Li J, Mao G, Huo Y, et al. Efficacy of folic acid supplementation in stroke prevention: a meta-analysis. Lancet 2007;369:1876-82.

43 Clarke R, Halsey J, Lewington A, Lonn E, Armitage J, Manson JE, et al. Effects of lowering homocysteine levels with $B$ vitamins on cardiovascukar disease, cancer and cause-specific mortality. Arch Intern Med (forthcoming).

44 Yokoyama M, Origasa H, Matsuzaki M, Matsuzawa Y, Saito Y, Ishikawa Y, et al. Effects of eicosapentaenoic acid on major coronary events in hypercholesterolaemic patients (JELIS): a randomised open-label, blinded endpoint analysis. Lancet 2007;369:1090-8.

45 Gissi-HF Investigators, Tavazzi L, Maggioni AP, Marchioli R, Barlera S, Franzosi MG, et al. Effect of $n-3$ polyunsaturated fatty acids in patients with chronic heart failure (the GISSI-HF trial): a randomised, double-blind, placebo-controlled trial. Lancet 2008;372:1223-30.

46 Kromhout D, Giltay EJ, Geleijnse JM, for the Alpha Omega Trial Group. $\mathrm{N}-3$ fatty acids and cardiovascular events after myocardial infarction. N Engl J Med 2010;363:2015-26.

47 Marchioli R, Barzi F, Bomba E, Chieffo C, Di Gregorio D, Di Mascio R, et al. Early protection against sudden death by $n-3$ polyunsaturated fatty acids after myocardial infarction: time-course analysis of the results of the Gruppo Italiano per lo Studio della Sopravvivenza nell'Infarto Miocardico (GISSI)-Prevenzione. Circulation 2002;105:1897-903.

48 London B, Albert C, Anderson ME, Giles WR, Van Wagoner DR, Balk E, et al. Omega-3 fatty acids and cardiac arrhythmias: prior studies and recommendations for future research: a report from the National Heart, Lung, and Blood Institute and Office of Dietary Supplements Omega-3 Fatty Acids and their Role in Cardiac Arrhythmogenesis Workshop. Circulation 2007;116:320-35.

Accepted: 16 September 2010 